\title{
Muffler Used on Civil Aircraft Air Condition Noise Reduction
}

\author{
Xudong Yan ${ }^{1+}$, Xuede Sun ${ }^{1}$, Dawei Wang ${ }^{1}$ and Zhi Yang ${ }^{1}$ \\ ${ }^{1}$ Commercial Aircraft Corporation of China, Ltd. ShangHai Aircraft Design and Research Institute, China
}

\begin{abstract}
Civil aircraft air condition noise is one of the main resource of cabin noise. Muffler is widely used to reduce aircraft air condition noise. Muffler acoustics performance is related to the interior structure and sound absorption material in muffler. The noise reduction effect is varied by simulation and laboratory test. Acoustics test result on aircraft with muffler indicate that cabin noise drop more than $6 \mathrm{~dB}$ with muffler.
\end{abstract}

Keywords: Civil aircraft, Cabin noise, Air condition, Muffler

\section{Introduction}

Civil aircraft cabin noise impacts the passenger comfort and clear communication. In order to increase the market competitiveness, The aircraft main manufacturer use all kinds of noise control technology during the design phase. The main resource of cabin noise of civil aircraft include engine vibration, fly pneumatic noise, air flow noise of air condition.

The air condition system of civil aircraft provide comfortable temperature and humidity environment for the aircrew and passengers. The airflow in the duct, rotate component in recirculation fan, compressor and turbine in air condition unit can produce plenty of noise. These noise finally enter into the aircraft cabin through the air condition duct. Air condition noise is one of the main resource of cabin noise .

Muffler is widely used to reduce aircraft air condition noise. It is installed on the air condition duct. The operation frequency, noise reduction, pressure loss are key factor for muffler performance. The muffler acoustics performance is related to interior structure and sound absorption material in muffler. Civil aircraft muffler has weight control and installation space restrict. Muffler structure optimize and sound absorption material selection is a difficult work during design phase.

This paper make acoustics finite element analysis on muffler with different design parameter. Muffler performance is verified through Laboratory test. Cabin noise reduction effect of muffler is test on aircraft.

\section{Aircraft Cabin Noise Resource from Air Condition System}

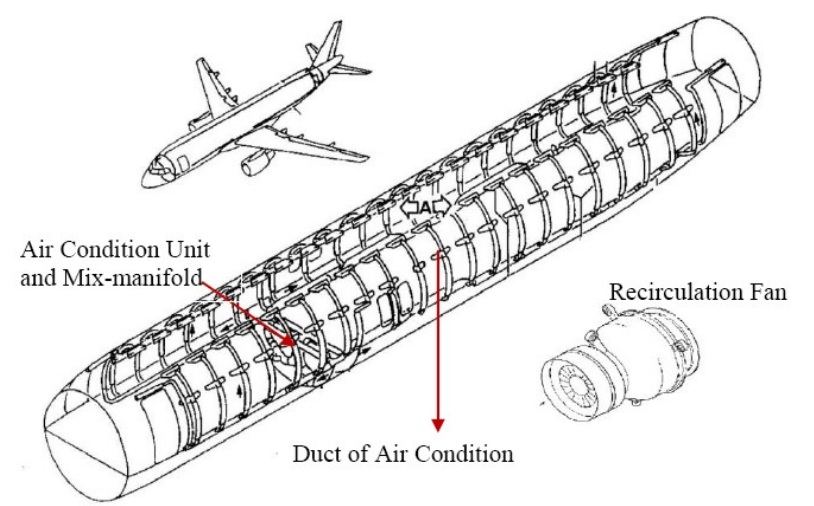

Fig. 1: Aircraft cabin noise resource from air condition system

Aircraft cabin noise resource from air condition system include Air Condition Unit, Hot Trim Air, Recirculation Fan, air flow in Duct and Mix-manifold ${ }^{[1]}$. It is mainly locate in $500 \sim 8000 \mathrm{~Hz}$ and produce

\footnotetext{
+ Corresponding author. Tel.: + 8613651669588; fax: +8602120860266.

E-mail address: bmw566@qq.com.
} 
high speech interference level ${ }^{[2-3]}$. Aircraft cabin noise resource components from air condition system is shown in figure 1. Sound Pressure Level at Recirculation Fan outlet is shown in figure 2.

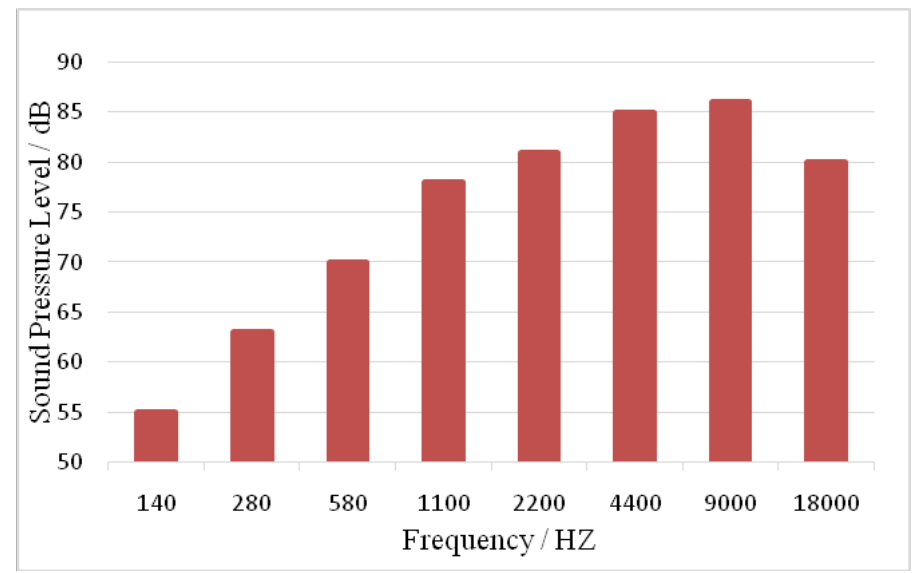

Fig. 2: Sound Pressure Level at Recirculation Fan outlet

\section{Muffler Performance by Finite Element Analysis}

Civil aircraft muffler normally use dissipative duct. The muffler is made up of expand duct and sound absorption material. The inner structure of muffler is shown in figure 3. Muffler finite element analysis is made with acoustics software COMSOL Multiphysics 5. The simulation model is shown in figure 4.

As is shown in figure 5 and figure 6, Noise reduction efficiency of muffler is related to expand ratio of duct and volume-weight of sound insulation cotton in muffler. The noise reduction is by means of sound transmission path mutation and cotton impedance. The bigger the expand ratio is, the better the noise reduction efficiency is. The bigger the volume-weight of sound insulation cotton is, the better the noise reduction efficiency is. Sound pressure level at frequency $500 \mathrm{~Hz}$ of muffler is shown in figure 7.

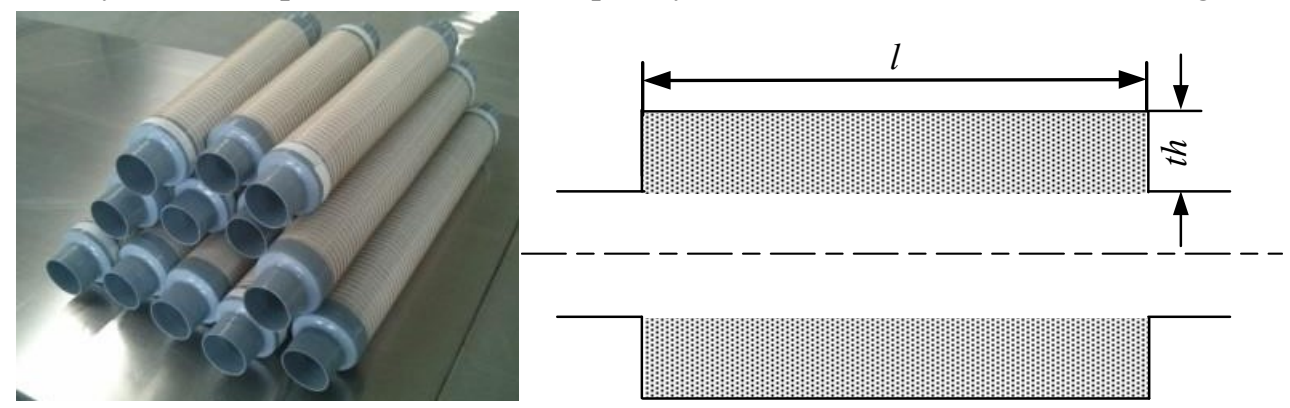

Fig. 3: Aircraft air condition Muffler inner structure

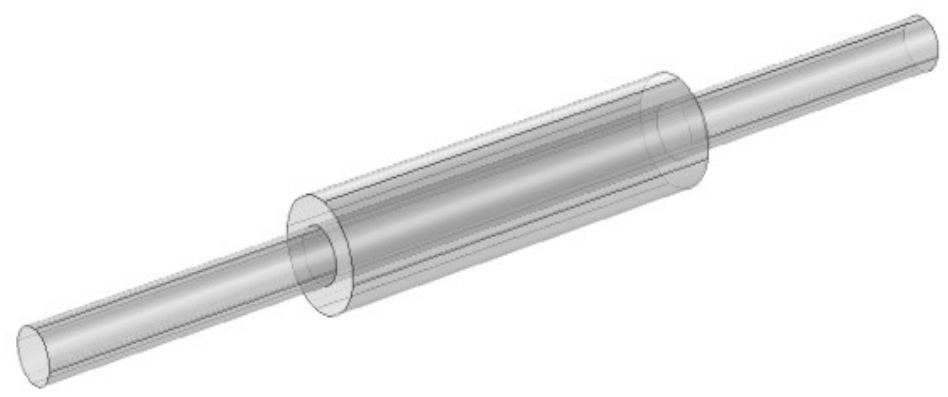

Fig.4: Simulation model 


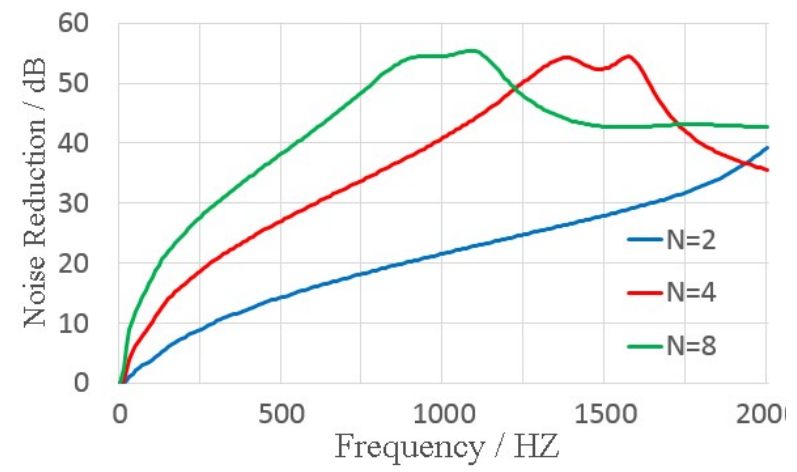

Fig. 5: Relationship between muffler noise reduction and expand ratio $\mathrm{N}$

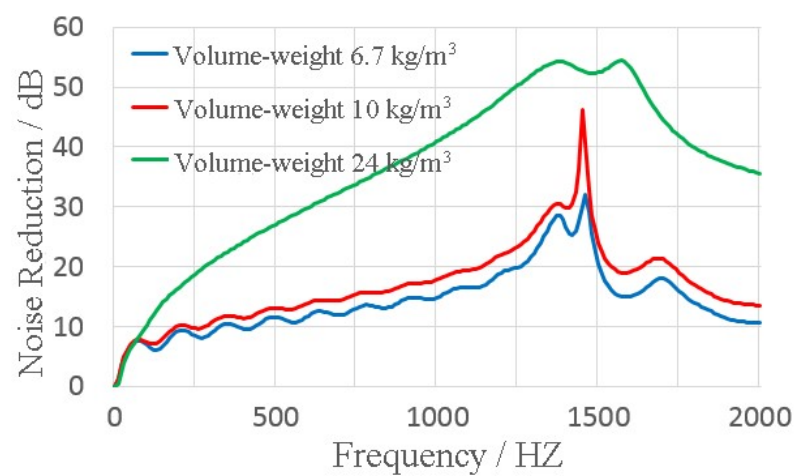

Fig. 6: Relationship between muffler noise reduction and sound insulation cotton

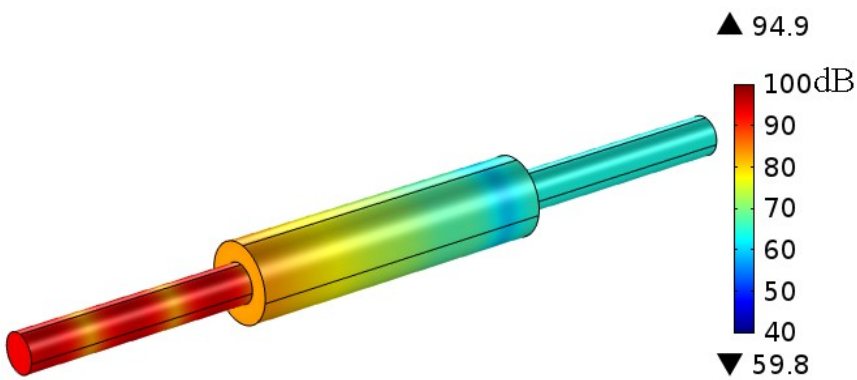

Fig. 7: Sound pressure level at frequency $500 \mathrm{~Hz}$

Air flow pressure loss of duct is very important for air condition system performance. The higher the air flow velocity is, the more noise will enter into the cabin. For this reason, the air flow velocity in aircraft air condition duct is limited below $20 \mathrm{~m} / \mathrm{s}$. Normally, the air flow velocity in duct that below cabin floor is about $15 \mathrm{~m} / \mathrm{s}$, the air flow velocity in duct that above cabin floor is about $10 \mathrm{~m} / \mathrm{s}^{[4]}$.

In the analysis, we assume the pressure at standard ambient atmosphere $1.01 \times 10^{5} \mathrm{~Pa}$. Air flow pressure loss (gage pressure) at velocity $15 \mathrm{~m} / \mathrm{s}$ and expand ratio $\mathrm{N}=4$ is shown in figure 8 . As is shown in table 1 , the higher the air flow velocity is, the more pressure loss will be.

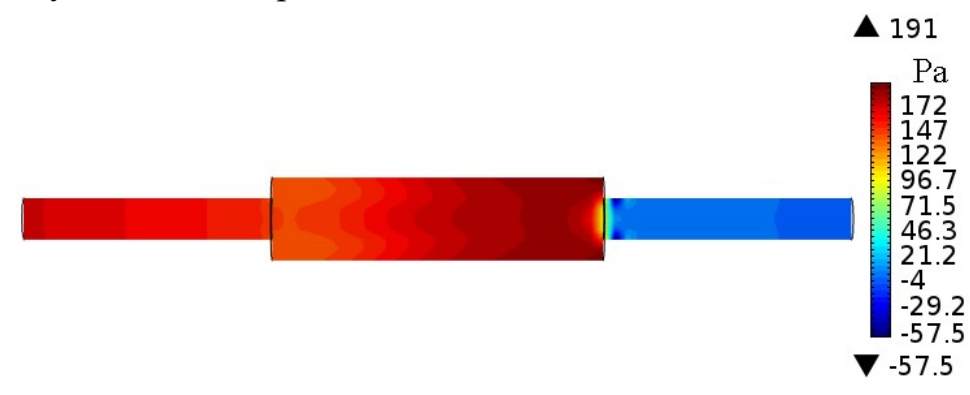

Fig.8: Air flow gage pressure at velocity $15 \mathrm{~m} / \mathrm{s}$ and expand ratio $\mathrm{N}=4$ 
Table 1: Muffler air pressure loss ( expand ratio $\mathrm{N}=4$ )

\begin{tabular}{|l|l|l|l|}
\hline Flow velocity $(\mathrm{m} / \mathrm{s})$ & 10 & 15 & 20 \\
\hline Pressure loss $(\mathrm{Pa})$ & 78.4 & 173.8 & 306.8 \\
\hline
\end{tabular}

\section{Acoustics Test without Muffler}

Acoustics test is performed at anechoic chamber with aircraft air condition component (Air Condition Unit, Recirculation Fan, Ventilation duct and mix-manifold). The laboratory test at anechoic chamber is shown in figure 9.
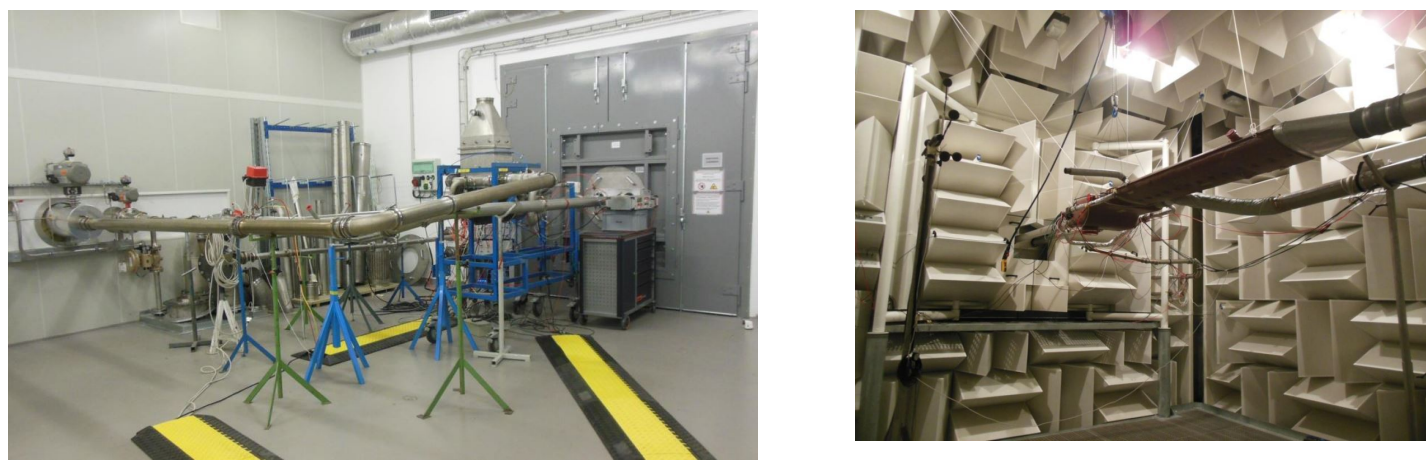

Fig. 9: Acoustics test performed at anechoic chamber with the aircraft air condition component

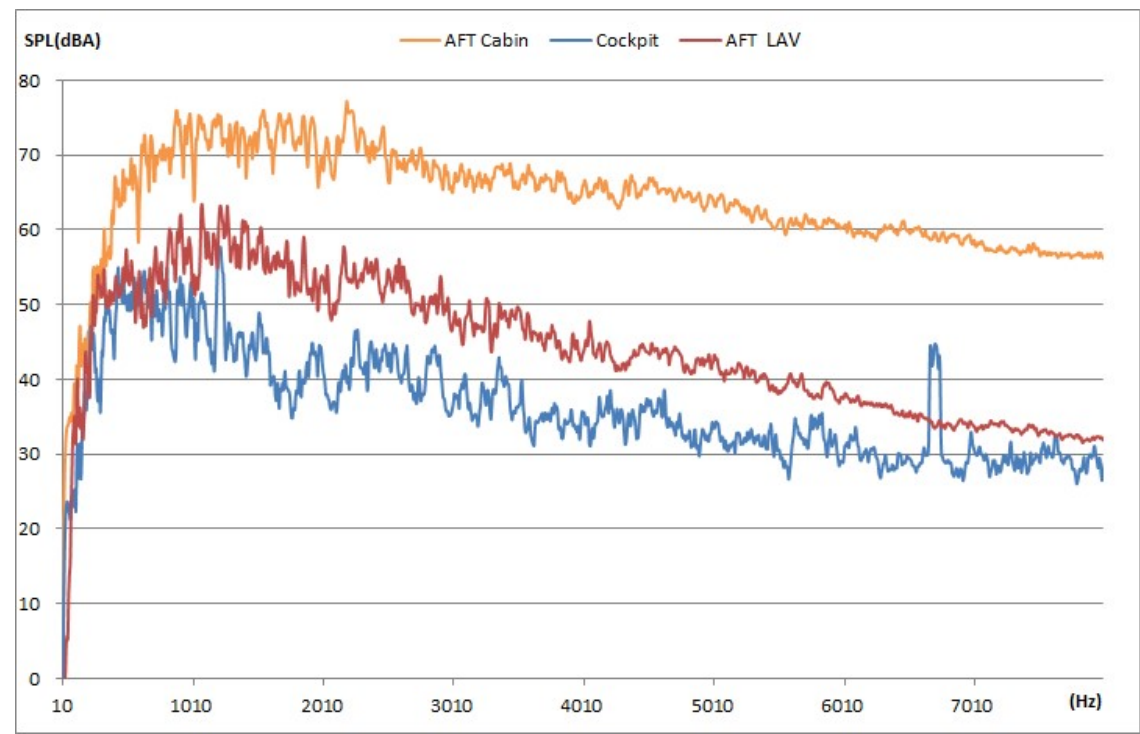

Fig. 10: Laboratory test result at anechoic chamber without muffler

The laboratory test result at anechoic chamber indicate that the main noise of air condition is higher than $250 \mathrm{~Hz}$ (intermediate frequency band and high-frequency band). These noise mainly is from the rotating parts in Recirculation Fan and Air Condition Unit. Test result is shown in figure 10.

Muffler is used to reduce air condition noise on the aircraft. For this reason, the noise level of air condition can be assumed as acoustics performance requirement of Muffler. Muffler acoustics performance requirement is shown in table 2 .

Table 2: Muffler acoustics performance requirement

\begin{tabular}{|l|c|c|c|c|c|c|c|c|c|}
\hline Frequency $/ \mathrm{Hz}$ & 31.5 & 63 & 125 & 250 & 500 & 1000 & 2000 & 4000 & 8000 \\
\hline Insertion loss $/ \mathrm{dB}$ & 0 & 0 & 0 & 3 & 6 & 16 & 24 & 24 & 28 \\
\hline
\end{tabular}

\section{Acoustics Test on Aircraft with Muffler}

Acoustics test is performed on aircraft on ground with muffler, test result is shown in table 3 . The test result indicate that muffler performance is outstanding, cabin noise drop more than $6 \mathrm{~dB}$ with muffler. Microphone position of acoustics test on aircraft is shown in figure $11^{[5-6]}$. 
Table 3: Acoustics test of aircraft cabin noise reduction with muffler

\begin{tabular}{|c|c|c|c|c|c|}
\hline & $\begin{array}{c}\text { Cabin test point } \\
\text { P1 }\end{array}$ & $\begin{array}{c}\text { Cabin test point } \\
\text { P2 }\end{array}$ & $\begin{array}{c}\text { Cabin test point } \\
\text { P3 }\end{array}$ & $\begin{array}{c}\text { Cabin test point } \\
\text { P4 }\end{array}$ & $\begin{array}{c}\text { Cabin test point } \\
\text { P5 }\end{array}$ \\
\hline $\begin{array}{c}\text { Aircraft without } \\
\text { muffler / dB }\end{array}$ & 79.63 & 79.53 & 80.90 & 80.22 & 81.42 \\
\hline $\begin{array}{c}\text { Aircraft with } \\
\text { muffler / dB }\end{array}$ & 70.79 & 70.03 & 71.53 & 71.19 & 75.04 \\
\hline Noise reduction / dB & 8.84 & 9.50 & 9.37 & 9.03 & 6.38 \\
\hline
\end{tabular}
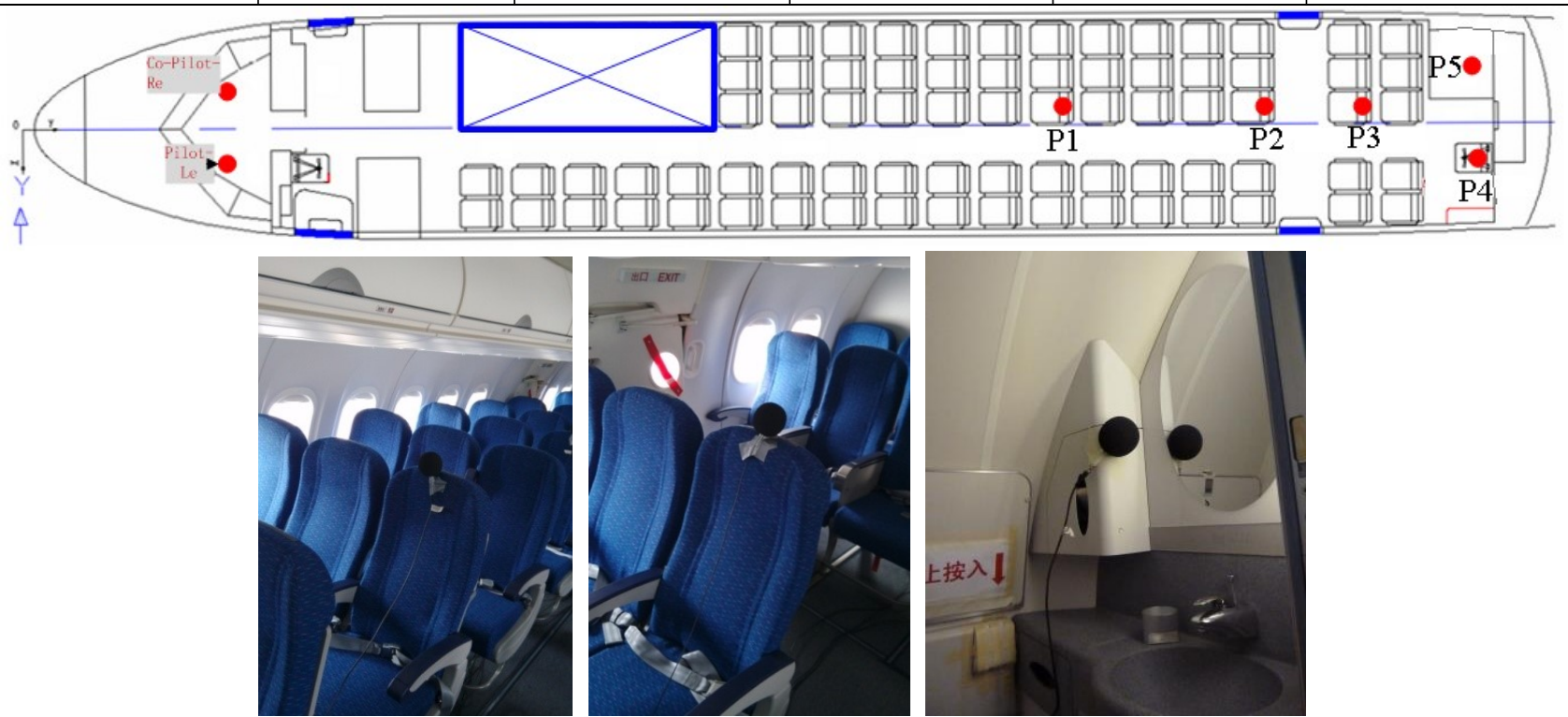

Fig. 11: Microphone position of acoustics test on aircraft

\section{Conclusion and Future Extension of Current Work}

This paper analyse aircraft cabin noise resource from air condition, perform acoustics test at anechoic chamber and aircraft. The conclusion of this paper is shown below.

1) Aircraft cabin noise resource from air condition system is made by Air Condition Unit, Hot Trim Air, Recirculation Fan, air flow in Duct and Mix-manifold. It is mainly locate in $500 \sim 8000 \mathrm{~Hz}$ and produce high speech interference level.

2) Noise reduction efficiency of muffler is related to expand ratio of duct and volume-weight of sound insulation cotton in muffler. The bigger the expand ratio is, the better the noise reduction efficiency is. The bigger the volume-weight of sound insulation cotton is, the better the noise reduction efficiency is.

3) Normally, Civil aircraft cabin noise will drop more than $6 \mathrm{~dB}$ with air condition muffler.

For future extension of current work, engineers are trying other solution to reduce the aircraft air condition noise, include:

1) Micropunch structure will be designed inside of the noise resource component (Recirculation Fan, Air Condition Unit and so on ).

2) Active noise reduction will be used around the noise resource component.

\section{References}

[1] SAE Acoustical Considerations for Aircraft Environmental Control System Design. AIR1826, 2004.06.

[2] Hu Xizhi. Civil Aircraft Cabin Noise Resource Analysis, Civil Aircraft design and research. 2011, 2 : 10-11

[3] Hu Xizhi. Discussion on the Research State on the Cabin Acoustics for Civil Aircraft, Civil Aircraft design and research. 2013, $2: 1-4$.

[4] SAE Air Conditioning Systems For Subsonic Airplanes. ARP85 Revision E, 2002.06.

[5] Lu Kean, Zeng Xiangyang, Yang Youliang. Acoustics Test, Machinery industry Press, 2012.05.

[6] Du Gonghuan, Zhu Zheming, Gong Xiufen. Acoustics foundation, Nan Jing University Press, 2010.08. 